\title{
COPE-SMARTER - A decision support system for analysing the challenges, opportunities and policy initiatives: A case study of electric commercial vehicles market diffusion in Denmark
}

\author{
Barfod, Michael Bruhn; Kaplan, Sigal; Frenzel, Ina; Klauenberg, Jens
}

\section{Published in:}

Research in Transportation Economics

Link to article, DOI:

10.1016/j.retrec.2016.04.005

Publication date:

2016

Document Version

Peer reviewed version

Link back to DTU Orbit

Citation (APA):

Barfod, M. B., Kaplan, S., Frenzel, I., \& Klauenberg, J. (2016). COPE-SMARTER - A decision support system for analysing the challenges, opportunities and policy initiatives: A case study of electric commercial vehicles market diffusion in Denmark. Research in Transportation Economics, 55, 3-11. https://doi.org/10.1016/j.retrec.2016.04.005

\section{General rights}

Copyright and moral rights for the publications made accessible in the public portal are retained by the authors and/or other copyright owners and it is a condition of accessing publications that users recognise and abide by the legal requirements associated with these rights.

- Users may download and print one copy of any publication from the public portal for the purpose of private study or research.

- You may not further distribute the material or use it for any profit-making activity or commercial gain

- You may freely distribute the URL identifying the publication in the public portal 


\section{COPE-SMARTER - A decision support system for analysing the challenges, opportunities and policy measures: A case study of electric commercial vehicles market diffusion in Denmark}

Michael B. Barfod ${ }^{\mathrm{a}}$, Sigal KAPLAN ${ }^{\mathrm{a}, \mathrm{b}^{*}}$, Ina Frenzel ${ }^{\mathrm{c}}$, Jens KLAUENBERG ${ }^{\mathrm{c}}$

${ }^{a}$ Technical University of Denmark, Department of Transport

${ }^{b}$ Faculty of Traffic Sciences, TU Dresden, 01062 Dresden, Germany

${ }^{\mathrm{c}}$ German Aerospace Center (DLR), Institute of Transport Research

* corresponding author

Department of Transport, Technical University of Denmark

Bygningstorvet 116B, 2800 Kgs. Lyngby, Denmark

Tel: + 45.4525.6559, Fax: +45.4593.6533, Email: siga @ transport.dtu.dk 


\begin{abstract}
Stakeholder's strategies in encouraging wide-scale market penetration depend on their perceptions. This study focuses on perceptions of Danish practitioners in policy-making organizations regarding the perceived challenges, opportunities and policy measures for the majority-market adoption of electric commercial vehicles (ECVs) in commercial sector in Denmark. We propose a new four-step expert-based technique, named COPE-SMARTER, for evaluating the market diffusion of environmental friendly technologies by combining a private case of SWOT analysis and Multi-criteria decision analysis (MCDA) methods. We focus on the perceptions regarding: (i) the potential promotional strength of motivators for ECV market penetration, (ii) the severity of the technological, financial, physical and operational challenges, (iii) the efficiency of policy initiatives in encouraging the market diffusion of ECVs, (iv) the expected market penetration rates by target year. The results show the strength of the COPESMARTER technique in generating a clear, coherent, and tractable evaluation. Severe challenges are financial, operational and technological, with high purchase prices being by far the most severe. The opportunities are financial and environmental, with overall savings in the long-term as the opportunity with the highest promotional strength. Effective policy-measures are low registration fee for ECVs, state subsidies for the purchase or use of ECVs, and emission-based taxes.
\end{abstract}

Key words: commercial vehicles; electric vehicles; decision makers; focus group; MCDA; SWOT. 


\section{Introduction}

Urban freight and commercial vehicles make up about $10 \%$ of the share of vehiclekilometre travelled, but they account for $50 \%$ of the COX emissions and $90 \%$ of the NOX and PM emissions (Feng and Figliozzi, 2013). The stress imposed by commercial vehicles on urban systems in terms of air pollution and noise is expected to increase, due to the fast growth of commercial vehicle activity (Feng and Figliozzi, 2012). A possible technology-oriented solution are electric commercial vehicles (ECVs) that, along with improvements in vehicle routing efficiency, can lead to mitigating the effect of commercial vehicles in urban areas without radical activity reduction (Feng and Figliozzi, 2013; Bakker et al., 2014).

The feasibility of ECVs as a possible solution depends on their wide-scale adoption in the commercial sector which depends on various stakeholders: consumers, planners, car manufacturers, and policy-making organizations. So far, studies have tried to shed light on the consumers' side by exploring the motivations and challenges for the introduction of ECVs and other alternative fuel vehicles (AFVs). Haller et al. (2007) focused on cost effectiveness and emission reductions based on an interim assessment of a local government's ten-year plan for converting from conventional fuel to AFVs. Bae et al. (2011) explored the likely effects of technological developments and instruments (i.e., technology, efficiency, fuel costs, emission regulations, tax rates, adaptation costs) on the adoption of AFVs by firms. Sierzchula et al. (2014) investigated the role of financial incentives, charging infrastructure, and local presence of production facilities on the market penetration of ECVs. Wikström et al. (2014) examined the relationship between ECVs' user satisfaction and confidence and ECVs' usage patterns and practical experience. Kirk et al. (2014) found that possible challenges for ECVs' adoption among fleet managers were fuel costs, recharging infrastructure, vehicle purchase costs and residual 
value, lack of knowledge and vehicle weight. Sierzchula (2014) found that American and Dutch organizations that adopted ECVs were interested in testing new technologies, receiving government grants, and improving the organization's public image. Kaplan et al. (2015) established a linkage between ECVs' procurement intentions and the theory of planned behavior, namely positive attitudes and subjective norms towards ECVs, familiarity with ECVs and perceived operational ease.

We sheds light on the perceptions of Danish practitioners in policy-making organizations as stakeholders in the process of ECVs' market adoption in Denmark. Previous studies addressing such stakeholders for exploring the market penetration of ECVs consulted policymakers within expert panels for assessing the importance of decision criteria to evaluate the suitability of AFVs via multi-criteria decision analysis, as means for overcoming the uncertainty involved with new technologies by reflecting upon the consumer choice. For the choice of ECVs in the commercial sector, Tzeng et al. (2005) requested bus manufacturers, researchers and bus operators to assess the importance of vehicle attributes related to costs, benefits, maintenance and operation for choosing the most suitable alternative fuel bus for public transport in urban areas in Taiwan. Yavuz et al. (2015) used an expert evaluation of multiple vehicle features, including energy efficiency, air pollution, maintenance costs, and comfort, for multi-criteria decision analysis aimed at choosing AFVs' selection of a home health-care service provider in the US. Nevertheless, in addition to the consumers' perspective, the perceptions of practitioners in policy-making organizations as stakeholders in the process of market adoption have a standalone merit because the stakeholder's strategies are dependent on their interests, perceptions and expectations. In fact, the gap between the objective overview of challenges, motivations and policy measures and their stakeholders' perceptions can be staggering. Based on a conceptual 
analysis, Browne et al. (2012) provided a long list of financial, technical, institutional and legal barriers that are hypothesized to be relevant to EVs' market diffusion, and suggested an equally wide range of economic, communication, infrastructure development and regulatory policies. Nevertheless, both the study of Bakker et al. (2014) and Kirk et al. (2014) showed that stakeholders have a much narrower perspective of policy measures in mind, depending on their interests and expectations.

We focus on the perceived challenges, opportunities and policy measures for majoritymarket adoption of ECVs in commercial vehicle fleets in Denmark. According to the Rogers' market diffusion model, which is relevant for technological innovation (see, e.g., Rogers, 2004), majority-market diffusion is achieved upon arriving to a critical mass of adopters from which market diffusion is self-sustaining. Thus, while early-market penetration depends on facilitating ECVs' adoption by innovating pioneers through pilot projects and financial incentives, majoritymarket adoption occurs when a certain threshold is reached in terms of alleviated challenges and policy incentives. Thus, we focus on the perceptions of practitioners in policy-making organizations regarding: (i) the potential promotional strength of motivators for ECVs' market penetration; (ii) the severity of the technological, financial, physical and operational challenges; (iii) the efficiency of policy initiatives in encouraging ECVs' market diffusion; (iv) the expected market penetration rates by target year.

The remainder of the paper is structured as follows. Section 2 introduces the research methods in terms of collected data and analysis. Then, results are presented and discussed in section 3. Last, conclusions and policy implications are drawn in Section 4. 


\section{Methods}

In this study, we propose a new expert-based technique for evaluating the possibility of market diffusion of new environmental friendly technologies by combining a private case of SWOT analysis for identifying strengths, weaknesses, opportunities and threats with MultiCriteria Decision Analysis (MCDA) methods based on the decomposition approach, namely the divide-and-conquer (DAC) principle. The method, which we name COPE-SMARTER, is aimed at identifying challenges, opportunities, and policies for promoting innovative environmental technology solutions, by using a combination of the SMARTER (Simple Multi-Attribute Rating Technique Exploiting Ranks) technique with Swing-Weights with a new importance-impact interpretation. In this study, the method is applied in the transport planning context, but it can be readily transferable for evaluating new technologies and action-protocols in other fields such as energy, water, environment, health-care, epidemiology, food and education.

The method requires a panel of stakeholders, which can be elicited by applying standard procedures (see, e.g., Sackman, 1974; Edwards and Barron, 1994), as conducted for example in the works of Shiftan et al. (2003) and Wang et al. (2014). In this study, 16 practitioners in policymaking organizations in Denmark were chosen as the main stakeholders. While standard procedures impose no limitations of sample size (see, e.g., Sackman, 1974; Edwards and Barron, 1994), the sample size in this study was determined by the conferencing procedure within a focus group arrangement, which required the stakeholder to meet, while assuring that the participants represent important policy-making organizations related to the ECV market in Denmark. Notably, in the case that a Delphi method is used the sample size can be larger. The main focus of this study is on practitioners in policy-making organizations because they have an important role in facilitating knowledge exchange and diffusion, aligning expectations across stakeholders, 
promoting campaigns, experiments, and pilot projects, designing development scenarios and trajectories through master plans, providing supportive environment stimulating entrepreneurs to take pioneering actions, generating funds, and enacting policy interventions. The importance of practitioners in policy-making organizations is highlighted by the findings of Roumboutsos et al. (2014) that indicate the need to transfer leadership from central authorities to municipal authorities in order to move from the initiation stage to the implementation stage of ECVs' logistics. Thus, the perceptions of practitioners in policy-making organizations regarding ECVs are important for understanding development trajectories and techno-institutional lock-ins affecting the wide-scale adoption of ECVs as a new technology.

After eliciting the panel of stakeholders, the proposed method has four consecutive steps. The first step consists of using the SWOT framework in order to identify the challenges and opportunities associated with the new technology, as well as the effective policy instruments for alleviating the challenges and seizing the opportunities as facilitators for technology diffusion. The challenges are challenges to be alleviated, which can be associated with the inherent product attributes (i.e., range, speed, price) or the consumer-technology interaction (e.g., range-anxiety). The opportunities are motivating factors that can be used to promote the technology and can be associated with inherent consumer attributes (i.e., cost and time saving skills, environmentally friendly attitudes and norms), and the consumer-technology interaction (i.e., perceived operational ease, cost-effectiveness, comfort, safety). The policy instruments are mechanisms that utilize the strengths and weaknesses of the organizational system in which the new technology and the consumer operate and interact, in order to resolve the challenges (e,g., moving to a green taxation system) and seize the opportunities (e.g., marketing campaigns that highlight the green aspects of ECVs). Using this structured framework helps in avoiding three 
important biases that lead to partial analysis. The first bias is a framing bias, namely focusing solely on challenges and policy instruments, while neglecting the opportunities for diffusion enhancement (see, e.g., Kirk et al., 2014). The second bias can derive either from memory-recall problems or from strategic-response bias, when stakeholders act on the basis of a narrow perspective that matches their interests and expectations (see, e.g., Bakker et al., 2014). The third bias is a confusion bias when technology solution attributes and policy interventions are both viewed as product related attributes, for example fuel costs (e.g., Yavuz et al. 2015;

Mohamadabadi et al., 2009).

The chosen challenges, opportunities and policy instruments derive from the results of the study of Kaplan et al. (2015), who proposed a comprehensive framework for understanding the motivations and challenges to the introduction of ECVs based on a survey across fleet managers in Austria, Denmark and Germany. The challenges consist of technological, financial, physical, operational and psychological challenges to be alleviated. The opportunities are related to the positive perception of ECVs. The policy instruments include both 'carrots', namely incentives for using ECVs, and 'sticks', namely policies for discouraging the use of conventional vehicles. The challenges, opportunities and policies are described in table 1.

\section{[Insert Table 1]}

The second and the third steps concern the rating of the challenges, opportunities and policy measures in terms of their relative importance and impact, respectively. In these two steps, taking a decomposition approach, each of the challenges, opportunities and policy measures are evaluated as separate items by applying the SMARTER and the Swing Weights procedures. While some of the items may have a synergetic or complimentary effects, a holistic evaluation is an extremely complex task which contains considerable random error, in particular 
when there is a large number of item combinations. However, taking a decomposition approach helps in defining the decision problem, allows considering a large number of items on multiple dimensions, and promotes communication of value conflicts among the participants (Fischer, 1997; Morera and Budescu, 1998).

For the second step, namely evaluating the importance of the challenges, opportunities and policy measures, we apply the SMARTER technique, proposed by Edwards and Barron (1994), which is an advancement of the SMART (Simple Multi-Attribute Rating Technique) suggested by von Winterfeldt and Edwards (1986). SMART is a MCDA method that allows evaluating finite number of decision alternatives with respect to a finite number of performance criteria.

The purpose of such an analysis is to rank the items in a subjective order of preference and, if possible, to rate the overall importance and performance of the items via the proper assignment of numerical grades (Belton and Stewart, 2002). The method is applied to evaluate the severity of the challenges, the potential of the opportunities and the efficiency of the policy measures with respect to their role in the market diffusion of ECVs. The challenge severity is defined as the importance of the challenge multiplied by its alleviation ease, the opportunity potential is defined as the importance of the opportunity multiplied by its promotional strength, and the efficiency of the policy measure is defined as its importance multiplied by its ability to cope with the challenges and seize the opportunities.

SMART, the original variant of the proposed method, is based on a linear additive model which implies that the overall value of a specific item is calculated as the total sum of the performance score multiplied with the weights. In the technique, ratings (scores) are assigned directly in the natural scales of the attributes. However, assigning exact numerical weights in 
SMART can be a difficult task which is susceptible to uncertainty and the confidence level associated with such weights. SMARTER overcomes this problem by requesting the participants to engage in a simpler cognitive task of ranking the items in order of importance. The, SMARTER assigns predetermined 'surrogate' weights to the criteria. These 'surrogate' weights are based on the assumption that generated weights may be more precise than weights produced by the participants. While a number of methods that enable the ranking to be translated into 'surrogate' weights representing an approximation of the 'true' weights have been developed, we use the Rank Order Distribution (ROD) weights, which provide the closest approximation to participants' preferences as shown by Roberts and Goodwin, (2002). ROD is a weight approximation method that assumes that valid weights can be elicited through direct rating. In the direct rating method the most important criterion is assigned a weight of 100 and the importance of the other criteria is then assessed to this benchmark. The obtained 'raw' weights are then normalised to sum to 1 . These ranges can be approximated by representing all of the inequalities by less-than-or-equal-to expressions. The uncertainty about the 'true' weights can then be represented by assuming uniform distribution for them. In order to determine ROD weights for general problems, it is needed to consider the probability distributions for the normalised weights that follow from the assumptions about the distributions of the 'raw' weights. The density functions are a series of piecewise equations. The means of each rank order distribution weights have been found mathematically and are provided by Roberts and Goodwin (2002).

In the third step, the analysis technique of swing weights is applied, which is usually considered to be the most correct theoretical method for eliciting criteria weights (Barfod and Salling, 2015). By using visually supported scales, participants consider the swing from worst to 
best performance for each item on a scale of 0-100. Notably, while the technique is commonly used for importance ranking, we take an untraditional interpretation for performance rating. Instead of simple importance rating, the third step concerns the rating of the challenges in terms of their severity, which comprises importance and alleviation ease, rating the opportunities in terms of their promotional strength (potential), and rating the policy measures in terms of their efficiency for the market diffusion of ECVs.

In the traditional approach for importance ranking, SMARTER and Swing Weights are considered as substitutionary (e.g., Wang et al., 2009; Barfod and Salling, 2014). However, in our proposed approach they measure different aspects and are thus complimentary. For example, some challenges may be considered important for the consumer but relatively easy to resolve, which reduces the overall challenge severity, while others may be considered as less important but more difficult to resolve, which increases the overall challenge severity. Therefore, the overall score is a function of the ratings obtained in step 2 and step 3 . The ROD weights, derived from the SMARTER procedure, represent the relative importance of the items. The swing rates represent the performance of each item. For each item and each participant, the overall score is calculated by multiplying the ROD weights and the swing weight to form a matrix of overall scores. The scores are normalized to one in order to obtain the normalized impact score for each item. The normalized scores are then averaged across the participants under the assumption that they have equal importance in the decision making process. Notably, while in the current study the items were rated with respect to a single objective of market diffusion, the method can be generalized to the attainment of multiple decision objectives by applying the multi-attribute utility theory (MAUT), the regret-based approach or the utility-regret model (see Wang et al., 
2014) as useful tools for calculating the overall score of the challenges, opportunities and policy measures.

The last step is a conferencing procedure where the participants are requested to state the market diffusion on ECVs for various target years as a trigger for reflecting in a group discussion on resolving the challenges, using the opportunities, and implementing the policy measures towards different target years. In the conferencing procedure, a majority and minority group decisions can be reached concerning the feasible target year for reaching a specific market diffusion level on the basis of the ease of resolving the challenges, using the opportunities and the efficiency of the policy initiatives. Last, additional perspectives and discussion points are raised and discussed to tackle the complexity of reaching the market diffusion goals in each target year.

\section{Results}

\subsection{Multi-criteria decision analysis}

The COPE-SMARTER scores representing the impact as the combination of importance and performance for the challenges, opportunities, and policy measures, are presented in Figures 1 and 3. The market penetration rate in each target year is provided in table 2. The practitioners in policy-making organizations generally agreed on the most severe challenges and the most effective policy measures, but had a more diverse view on the best opportunities.

\section{[Insert Figure 1]}

Regarding the challenges, the vast majority of the interviewed practitioners in policymaking organizations perceived the financial, operational and technological challenges as the most severe ones. The physical infrastructure and safety, with an overall score close to zero, were hardly perceived as challenges at all. The most severe challenge unanimously perceived by 
the panel was by far the high purchase price of ECVs. The second most severe challenge was perceived to be the ECVs' range that was considered as inadequate for accommodating the range needs of firms for their daily tours. The third and fourth most severe challenges were close in their scores and were related to winter operation (i.e., reliability in winter conditions and need to use the battery power for heating). The stop pattern of vehicles in their daily tours (i.e., having the possibility to stop for $30 \mathrm{~min}$. or more during the day) was perceived by seven experts as a significant challenge, but the overall score of this challenge is by far lower than the scores of the other operational challenges. Nevertheless, in a minority opinion one expert viewed the stop pattern of companies as the most severe challenge.

Unlike in the case of the unanimous decision regarding the severity of the challenges, the practitioners were divided into three groups when looking at the opportunity with the highest promotional strength. The leading opportunities were the long-term environmental benefits, which were viewed by five practitioners as the opportunity with the highest score, the general cost savings, and the suitability of ECVs to the firms' needs in terms of vehicle range. Each of these opportunities was viewed by four practitioners as the one with the highest score. Nevertheless, when considering the three opportunities with the highest potential, more than ten of the practitioners in policy-making organizations agree that the two financial motivations of cost-savings in daily use (i.e., energy costs and overall savings in the long-term) should be included among the three opportunities with the highest promotional strength, and seven practitioners viewed the long-term environmental benefits as one of the two opportunities with the highest promotional strength. ECVs as a tool for generating good public image and their suitability to the firms' needs were viewed among the three best opportunities by five and six practitioners, respectively. The opportunity for the firm to be a pioneer and an innovator, and the 
perception that ECVs are cool to drive, were viewed as the second or third best opportunity by two and three practitioners, respectively.

\section{[Insert Figure 2]}

Regarding the efficiency of the policy measure, the practitioners in policy-making organizations almost unanimously agreed that in general 'carrot' are more effective than 'stick' policy measures. Most of the practitioners ranked a combination of two 'carrots' and one 'stick' among the three most effective policy measures. In terms of type, the three policy measures that were ranked as the most or second most effective by the practitioners are financial policy measures: low registration fees for ECVs, state subsidies for the purchase or use of ECVs, and emission-based taxes on vehicles. Among these three measures, low registration fees for ECVs were by far the most effective policy measure, considered by almost all the practitioners to be either the most or the second most effective one. High gasoline and diesel prices were considered as the three most effective measures among a third of the participants. Free parking was considered to be the third most effective policy measure by a third of the participants. Limitations on carbon emissions or the purchase of conventional vehicles were considered by far the least effective policy measures. The practitioners ranked the policy measures independently and were not requested to choose a preferred policy package. Nevertheless, looking at the three most effective measures ranked by each participant, the combination of low registration tax and emission-based taxes was chosen by eight practitioners as most effective, and the combination of low registration tax and state subsidies was chosen by seven practitioners. Nevertheless, the combination of low registration taxes, state subsidies and low emission taxes were ranked among the three most effective measures only by three participants.

[Insert Figure 3] 
Almost of the practitioners in policy-making organizations agreed on the market penetration rate for ECVs per target year. The agreed penetration rate was 5-10\% until 2020, 20$30 \%$ until 2030, $60 \%$ until 2050, and $80 \%$ until 2070. Interestingly, in the conferencing procedure the practitioners agreed that ECVs will not reach their full potential market penetration because they will compete with other technological solutions for low-emission vehicles. In a minority opinion, two practitioners perceived a much faster penetration rate of 40$50 \%$ until 2020 and 70-100\% until 2030. These two practitioners perceived the high purchase price of ECVs as the most important challenge, the advantages in terms of energy costs and general cost savings as the opportunities with the highest promotional effect, and high petrol and diesel prices and low registration fee for electric vehicles as the most efficient policy measures. Thus, these two practitioners viewed a more radical change in the financial aspects of car use that will lead to a faster market penetration of ECVs.

\section{[Insert Table 2]}

\subsection{Conferencing procedure}

In the conferencing procedure, the practitioners pointed out that, in order to achieve significant impact, it is necessary to decide upon an effective a policy-package consisting of several policy measures, for creating a synergetic effect. Moreover, they pointed out that an important challenge for ECVs' market penetration is associated with prejudice against this new technology, which is partly related to the lack of information and partly to the collapse of "Better Place" in Denmark, and thus better information diffusion about the features of ECVs' technology and the opportunities associated with them may help in promoting their market diffusion. A longer discussion questioned the focus on ECVs as a sole technological solution. Namely, the practitioners underlined that policy-making efforts should be focused on challenges and 
opportunities that help promoting low-emission vehicle solutions at large. Technical solutions and improvements were discussed, and a common agreement was that a pure electrical solution is only a step on the way moving from fossil fuels, and perceived that a much larger share of market penetration can be achieved with a mixture of various types of AFV solutions. The reasons provided by the practitioners were that the technology of ECVs as we know it today may radically change in the future, and the existence of a wide variety of low-emission vehicle technologies, which will allow the firms to choose the most effective technological solution according to their needs, preferences and resources.

\subsection{Comparison with the firm perspective}

Comparing the results of this study with the results of Kaplan et al. (2015) for the Danish case study provides valuable information regarding the possible similarities and gaps between the perspective of practitioners in policy-making organisations and the perspective of firms as potential consumers of ECVs. The study collected information from 677 Danish firms, drawn from a representative sample, about their current daily tour and stop patterns, and their ECV procurement intentions and their attitudes, norms and perceived operational ease of ECVs.

The observed activity pattern consisted of the average number of depot-based daily tours, the average daily tour duration and the number of pick-up/drop-off and rest stops per tour for a representative vehicle, the share of vehicle fleet that have a tour length from under $50 \mathrm{~km}$ to over $400 \mathrm{~km}$ in increments of $50 \mathrm{~km}$, and the share of the vehicle fleet that has at least one 30-minute stop. The distribution of the activity pattern of the firms is provided in table 3. The average daily tour length of $81.3 \%$ of the firms is shorter than 100 kilometres and in almost half of the companies at least $60 \%$ of the vehicles include at least one 30 minute stop in their daily pattern.

[Insert Table 3] 
The attitudes towards ECVs comprised interest in ECVs, perceived level of familiarity with ECV technology, positive attitudes towards ECVs as an environmentally friendly and energy saving transport mode, and perception of ECVs as a passing trend. The subjective norms referred to other firm managers and politicians in the same industrial sector and in geographical proximity to the firm, and regarded conversations about ECVs use and purchase, positive opinions about ECVs, and expectations of politicians that ECVs would be introduced in this industrial sector. The perceived behavioural control targeted perceived difficulties to use EVs, namely high price, limited range and speed, lack of service network and recharging infrastructure, maintenance ease, road safety, parking considerations, energy cost-savings and financial purchase incentives. The attitudinal items were rated on a 5-point Likert scale ranging from completely disagree to fully agree. The results of the attitudinal items that correspond to the current study are provided in table 4 . In terms of the challenges, the majority of the fleet managers perceive that the purchase price is too high (75.6\%) and that there is missing recharging infrastructure (59.3\%). Almost half of the fleet managers answered "neither agree nor disagree" to the questions about the reliability and safety of ECVs, indicating a possible lack of knowledge or experience with ECVs. Nevertheless, less than $20 \%$ of the fleet managers think that ECVs are unreliable or unsafe. Regarding the opportunities, $76.2 \%$ of the fleet managers think that ECVs have long-term environmental benefits, while only $41.1 \%$ view them as a potential opportunity for general cost savings. 51.1\% view ECVs as a tool for generating good public image and $47.1 \%$ agree that ECvs are suitable for the driving range needs of the firms. Regarding the policy measures, $64.3 \%$ and $53.2 \%$ of the fleet managers, respectively, agree that tax benefits and free parking are beneficial for encouraging the use of ECVs.

\section{[Insert Table 4]}




\section{Conclusions}

We focus on the perceptions of practitioners in policy-making organizations regarding the severity of the challenges, the opportunities and the policy measures for the market diffusion of ECVs. These perceptions are important for the diffusion of ECVs because stakeholder's strategies in encouraging their wide-scale market penetration are dependent on their perceptions. While most previous research on the market penetration of ECVs focused on the demand side from the firm perspective, understanding the perspective of practitioners in policy-making organizations in addition to the firms will contribute to a dialogue that will eventually lead to a successful market diffusion.

To perform the analysis, we propose a new four-step expert-based technique, named COPE-SMARTER, for evaluating the possibility of market diffusion of new environmental friendly technologies by combining a private case of SWOT analysis for identifying strengths, weaknesses, opportunities and threats with Multi-Criteria Decision Analysis (MCDA) methods based on the decomposition approach, namely the divide-and-conquer (DAC) principle. A conferencing procedure forms the last stage of the method in order to generate in-depth discussion and an integrated view. Using the COPE-SMARTER methodology, we provide a rigorous quantitative evaluation of the severity of the challenges, the promotional strength of opportunities and the efficiency of policy measures. The evaluation results show that the proposed COPE-SMARTER is an efficient and easy to implement MCDA tool that produces clear, coherent, and tractable results for an overall assessment of importance-performance, easily detects minority and majority opinions, and is readily applied in decision making processes of both small and large group sizes. 
The most severe challenges perceived by practitioners in policy-making organizations were financial, operational, and technological, with high purchase prices being by far the most severe challenge followed by vehicle range and winter operation issues. The opportunities with the highest perceived promotional strength were financial and environmental, with overall savings in the long-term as the opportunity with the highest promotional strength, followed by energy cost savings and long-term environmental benefits. The policy-measures that were perceived as most effective were low registration fees for ECVs, state subsidies for the purchase or use of ECVs, and emission-based taxes on vehicles. The policy-packages that were viewed as the most efficient combine 'carrot' and 'stick' policy measures, with more 'carrots' than 'sticks'.

Comparing the results of this study with the results of Kaplan et al. (2015) for the Danish case study provides valuable information regarding the possible similarities and gaps between the perspective of practitioners in policy-making organizations and the perspective of firms as potential consumers of ECVs. The firm managers and practitioners in policy making organizations agree that the main challenge to resolve is the high purchase price of ECVs. However, there is a mismatch between the fleet managers and the practitioners in policy-making organizations regarding the importance of driving range versus recharging infrastructure. The practitioners in policy making organizations view the driving range as a secondary challenge and disregarded the importance of public charging infrastructure, while fleet managers indicated that the driving range of their vehicles is relatively short and that ECVs are suitable for accommodating their needs, but indicated the lack of charging infrastructure. Regarding the opportunities, practitioners in policy-making organization perceive the environmental benefits of ECVs as having a good promotional strength, and indeed most fleet managers view this advantage. Nevertheless, Fleet managers do not view the cost savings related to ECVs while 
policy makers almost unanimously view the cost saving as the best opportunity for ECV market penetration. In addition the practitioners in policy-making organizations overlook the potential promotional strength of ECVs as a tool for generating a good public image. Last there is a wide agreement regarding the value of tax benefits as an efficient policy measure for encouraging ECV market penetration.

\section{Acknowledgments}

A part of the study was conducted during the stay of Sigal Kaplan as an "EleonoreTrefftz" Guest Professor in Faculty of Traffic Sciences, TU Dresden, as part of the TU-Dresden Excellence program, supported by the German Research Foundation. The study forms part of the project "SELECT - Suitable Electro Mobility for Commercial Transport", supported by the European Union and national funding authorities in Austria, Denmark and Germany.

\section{References}

Bae, S.H., Sarkis, J., Yoo, C.S., 2001. Greening transportation fleets: Insights from a two-stage game theoretic model. Transportation Research Part E: Logistics and Transportation Review, 47 (6), 793-807.

Bakker, S., Maat, K., van Wee, B., 2014. Stakeholders interests, expectations, and strategies regarding the development and implementation of electric vehicles: The case of the Netherlands. Transportation Research Part A: Policy and Practice, 66, 52-64.

Barfod, M.B., Salling, K.B., 2015. New composite decision support framework for strategic and sustainable transport appraisals. Transportation Research Part A: Policy and Practice, $72,1-15$.

Belton, V., Stewart, T.J., 2002. Multi Criteria Decision Analysis: An integrated approach. Kluwer Academic Publishers, London, United Kingdom. 
Browne, M., Cudeck, R., 1993. Alternative ways of assessing model fit. In: Bollen, K., \& Long, S. (Eds.), Testing Structural Equation Models, Sage, Newbury Park, NJ.

Edwards W., Barron F.H., 1994. SMARTS and SMARTER: Improved simple methods for multiattribute utility measurement. Organizational Behavior and Human Decision Processes, 60, 306-325.

Feng, W., Figliozzi, M.A., 2012. Conventional vs Electric Commercial Vehicle Fleets: A Case Study of Economic and Technological Factors Affecting the Competitiveness of Electric Commercial Vehicles in the USA. Procedia - Social and Behavioral Sciences, 39, 702711.

Feng, W., Figliozzi, M.A., 2013. An economic and technological analysis of the key factors affecting the competitiveness of electric commercial vehicles: A case study from the USA market. Transportation Research Part C: Emerging Technologies, 26, 135-145.

Fischer, G.W., 1977. Convergent validation of decomposed multi-attribute utility assessment procedures for risky and riskless decisions. Organizational Behavior and Human Decision Processes, 18, 295-315.

Haller, M., Welch, E., Lin, J., Fulla, S., 2007. Economic costs and environmental impacts of alternative fuel vehicle fleets in local government: An interim assessment of a voluntary ten-year fleet conversion plan. Transportation Research Part D: Transport and Environment, 12(3), 219-230.

Kaplan, S., Gruber, J., Frenzel, I., Reinthaler, M., Klauenberg. J., 2015. Procurement intentions of electric vehicles in the commercial sector: a model based on the theory of planned behaviour. Transportation Research Part A: Policy and Practice, under review. 
Kirk, J.L., Bristow, A.L., Zanni, A.M., 2014. Exploring the market for Compressed Natural Gas light commercial vehicles in the United Kingdom. Transportation Research Part D: Transport and Environment, 29, 22-31.

Morera, O. F., Budescu D.V., 1998. A psychometric analysis of the "Divide and Conquer" principle in multicriteria decision making. Organizational Behavior and Human Decision Processes, 75 (3), 187-206.

Mohamadabadi, H. S., Tichkowsky, G., Kumar, A., 2009. Development of a multi-criteria assessment model for ranking of renewable and non-renewable transportation fuel vehicles. Energy, 34,112-125.

Roberts, R., Goodwin, P., 2002. Weight approximations in multi-attribute decision models. Journal of Multi-Criteria Decision Analysis, 11, 291-303.

Rogers, E.M., 2004. A prospective and retrospective look at the diffusion model. Journal of Health Communication, 9, 13-19.

Roumboutsos, A., Kapros, S., Vanelslander, T., 2014. Green city logistics: Systems of Innovation to assess the potential of E-vehicles. Research in Transportation Business \& Management, 11, 43-52.

Sackman, H., 1974. Delphi assessment: expert opinion, Forecasting and group process. RAND report R-1283-PR, pp. 7-8.

Shiftan, Y., Kaplan, S., Hakkert S., 2003. Scenario building as a tool for planning a sustainable transportation system. Transportation Research Part D: Transport and Environment, 8 (5), 323-342. 
Sierzchula, W., 2014. Factors influencing fleet manager adoption of electric vehicles. Transportation Research Part D: Transport and Environment, 31, 126-134.

Sierzchula, W., Bakker, S., Maat, K., van Wee, B., 2014. The influence of financial incentives and other socio-economic factors on electric vehicle adoption. Energy Policy, 68, 183194.

Tzeng, G.H., C.W. Cheng-Wei Lin, Opricovic, S., 2005. Multi-criteria analysis of alternativefuel buses for public transportation. Energy Policy, 33, 1373-1383.

Von Winterfeldt, D., Edwards, W., 1986. Decision Analysis and Behavioural Research. Cambridge University Press, New York, United States of America.

Wang, Y., Monzon, A., Di Ciommo, F., Kaplan, S., 2014. An integrated transport planning framework involving a combined utility-regret approach. Transportation Research Record, 2429, 59-66.

Wang, J.J., Jing, Y.Y., Zhang, C.F., Zhao, J.H., 2009. Review on multi-criteria decision analysis aid in sustainable energy decision-making. Renewable \& Sustainable Energy Reviews, $132,2263-2278$.

Wikström, M., Hansson, L., Alvfors, P., 2014. Socio-technical experiences from electric vehicle utilization in commercial fleets. Applied Energy, 123, 82-93.

Yavuz, M., Oztaysi, B., Onar, S.C., Kahraman, C. (2015). Multi-criteria evaluation of alternative-fuel vehicles via a hierarchical hesitant fuzzy linguistic model. Expert Systems with Applications, 42, 2835-2848. 


\begin{tabular}{|c|c|c|c|c|c|c|c|c|c|c|}
\hline \multirow{2}{*}{$\begin{array}{l}\text { Description } \\
\text { Participant } \\
\end{array}$} & \multirow{2}{*}{$\begin{array}{l}\text { Financial } \\
\text { C1 }\end{array}$} & \multicolumn{4}{|c|}{ Physical } & \multicolumn{2}{|c|}{ Operational } & \multicolumn{2}{|c|}{ Technological } & \multirow{2}{*}{$\begin{array}{l}\text { Safety } \\
\text { C10 } \\
\end{array}$} \\
\hline & & $\mathrm{C} 2$ & $\mathrm{C} 3$ & $\mathrm{C} 4$ & $\mathrm{C} 5$ & C6 & $\mathrm{C7}$ & $\mathrm{C} 8$ & $\mathrm{C9}$ & \\
\hline$\# 1$ & 0.256 & 0.089 & 0.061 & 0.014 & 0.002 & 0.206 & 0.029 & 0.181 & 0.157 & 0.005 \\
\hline$\# 2$ & 0.268 & 0.146 & 0.020 & 0.015 & 0.005 & 0.215 & 0.064 & 0.093 & 0.168 & 0.005 \\
\hline \#3 & 0.012 & 0.051 & 0.062 & 0.050 & 0.037 & 0.213 & 0.266 & 0.167 & 0.127 & 0.015 \\
\hline$\# 4$ & 0.265 & 0.092 & 0.010 & 0.063 & 0.126 & 0.213 & 0.040 & 0.166 & 0.022 & 0.002 \\
\hline$\# 5$ & 0.232 & 0.056 & 0.094 & 0.072 & 0.017 & 0.186 & 0.164 & 0.126 & 0.048 & 0.004 \\
\hline$\# 6$ & 0.252 & 0.177 & 0.000 & 0.282 & 0.000 & 0.021 & 0.054 & 0.115 & 0.098 & 0.000 \\
\hline \#7 & 0.198 & 0.108 & 0.036 & 0.012 & 0.018 & 0.317 & 0.174 & 0.073 & 0.061 & 0.003 \\
\hline \#8 & 0.254 & 0.109 & 0.030 & 0.061 & 0.002 & 0.093 & 0.077 & 0.191 & 0.168 & 0.015 \\
\hline$\# 9$ & 0.337 & 0.065 & 0.032 & 0.003 & 0.000 & 0.181 & 0.078 & 0.159 & 0.126 & 0.019 \\
\hline$\# 10$ & 0.309 & 0.170 & 0.126 & 0.072 & 0.000 & 0.035 & 0.017 & 0.044 & 0.221 & 0.006 \\
\hline \#11 & 0.251 & 0.137 & 0.057 & 0.028 & 0.019 & 0.180 & 0.108 & 0.099 & 0.116 & 0.005 \\
\hline \#12 & 0.235 & 0.166 & 0.050 & 0.040 & 0.005 & 0.264 & 0.126 & 0.099 & 0.015 & 0.000 \\
\hline$\# 13$ & 0.243 & 0.065 & 0.132 & 0.113 & 0.023 & 0.048 & 0.005 & 0.195 & 0.172 & 0.005 \\
\hline$\# 14$ & 0.322 & 0.000 & 0.000 & 0.084 & 0.000 & 0.173 & 0.139 & 0.110 & 0.173 & 0.000 \\
\hline Average & 0.245 & 0.102 & 0.051 & 0.065 & 0.018 & 0.167 & 0.096 & 0.130 & 0.119 & 0.006 \\
\hline
\end{tabular}

Figure 1. The scores of the severity of the challenges for the market diffusion of ECVs 


\begin{tabular}{|c|c|c|c|c|c|c|c|c|}
\hline \multirow{2}{*}{\begin{tabular}{|l|} 
Description \\
Participant
\end{tabular}} & \multirow{2}{*}{\begin{tabular}{|l|} 
Technological \\
01
\end{tabular}} & \multicolumn{2}{|c|}{ Operational } & \multirow{2}{*}{\begin{tabular}{|l|} 
Environmental \\
O4
\end{tabular}} & \multicolumn{2}{|c|}{ Financial } & \multicolumn{2}{|c|}{ Branding } \\
\hline & & 02 & $\mathrm{O3}$ & & 05 & 06 & 07 & 08 \\
\hline$\# 1$ & 0.000 & 0.296 & 0.192 & 0.008 & 0.255 & 0.046 & 0.062 & 0.023 \\
\hline \#2 & 0.036 & 0.101 & 0.004 & 0.337 & 0.197 & 0.262 & 0.048 & 0.016 \\
\hline \#3 & 0.091 & 0.056 & 0.115 & 0.017 & 0.155 & 0.209 & 0.303 & 0.053 \\
\hline \#4 & 0.000 & 0.000 & 0.000 & 1.000 & 0.000 & 0.000 & 0.000 & 0.000 \\
\hline \#5 & 0.065 & 0.192 & 0.087 & 0.037 & 0.264 & 0.205 & 0.127 & 0.024 \\
\hline$\# 6$ & 0.128 & 0.095 & 0.175 & 0.267 & 0.066 & 0.219 & 0.040 & 0.009 \\
\hline \#7 & 0.074 & 0.313 & 0.055 & 0.029 & 0.182 & 0.243 & 0.094 & 0.011 \\
\hline$\# 8$ & 0.059 & 0.032 & 0.016 & 0.278 & 0.216 & 0.105 & 0.133 & 0.162 \\
\hline \#9 & 0.145 & 0.015 & 0.008 & 0.078 & 0.257 & 0.331 & 0.109 & 0.058 \\
\hline$\# 10$ & 0.238 & 0.087 & 0.054 & 0.110 & 0.035 & 0.306 & 0.156 & 0.014 \\
\hline \#11 & 0.227 & 0.171 & 0.069 & 0.051 & 0.088 & 0.088 & 0.293 & 0.014 \\
\hline$\# 12$ & 0.034 & 0.318 & 0.114 & 0.007 & 0.197 & 0.247 & 0.068 & 0.015 \\
\hline \#13 & 0.057 & 0.031 & 0.015 & 0.129 & 0.089 & 0.177 & 0.269 & 0.232 \\
\hline \#14 & 0.085 & 0.258 & 0.012 & 0.178 & 0.036 & 0.258 & 0.113 & 0.061 \\
\hline \#15 & 0.076 & 0.186 & 0.096 & 0.022 & 0.320 & 0.248 & 0.045 & 0.007 \\
\hline$\# 16$ & 0.010 & 0.000 & 0.000 & 0.412 & 0.198 & 0.284 & 0.039 & 0.058 \\
\hline Average & 0.090 & 0.134 & 0.063 & 0.185 & 0.160 & 0.202 & 0.119 & 0.047 \\
\hline
\end{tabular}

Figure 2. The scores of the potential marketing strength of the opportunities for the market diffusion of ECVs 


\begin{tabular}{|c|c|c|c|c|c|c|c|}
\hline Description & & "Carrots" & & & "Stic & cks" & \\
\hline Participant & P1 & P2 & P3 & P4 & P5 & P6 & P7 \\
\hline \#1 & 0.126 & 0.250 & 0.331 & 0.193 & 0.066 & 0.009 & 0.026 \\
\hline \#2 & 0.182 & 0.052 & 0.278 & 0.331 & 0.108 & 0.009 & 0.040 \\
\hline \#3 & 0.019 & 0.369 & 0.102 & 0.248 & 0.104 & 0.039 & 0.120 \\
\hline \#4 & 0.171 & 0.037 & 0.238 & 0.071 & 0.354 & 0.014 & 0.115 \\
\hline \#5 & 0.016 & 0.240 & 0.302 & 0.124 & 0.115 & 0.164 & 0.040 \\
\hline \#6 & 0.021 & 0.077 & 0.319 & 0.241 & 0.046 & 0.175 & 0.121 \\
\hline \#7 & 0.100 & 0.059 & 0.248 & 0.370 & 0.178 & 0.005 & 0.039 \\
\hline \#8 & 0.216 & 0.315 & 0.264 & 0.108 & 0.066 & 0.004 & 0.026 \\
\hline \#9 & 0.067 & 0.127 & 0.333 & 0.035 & 0.252 & 0.004 & 0.183 \\
\hline \#10 & 0.177 & 0.105 & 0.243 & 0.322 & 0.077 & 0.051 & 0.025 \\
\hline \#11 & 0.033 & 0.064 & 0.318 & 0.214 & 0.175 & 0.042 & 0.155 \\
\hline$\# 12$ & 0.018 & 0.254 & 0.336 & 0.208 & 0.128 & 0.004 & 0.054 \\
\hline$\# 13$ & 0.251 & 0.182 & 0.332 & 0.090 & 0.093 & 0.043 & 0.009 \\
\hline$\# 14$ & 0.027 & 0.194 & 0.194 & 0.130 & 0.194 & 0.130 & 0.130 \\
\hline \#15 & 0.166 & 0.010 & 0.203 & 0.403 & 0.131 & 0.021 & 0.065 \\
\hline \#16 & 0.092 & 0.160 & 0.043 & 0.135 & 0.220 & 0.021 & 0.328 \\
\hline Average & 0.105 & 0.156 & 0.255 & 0.201 & 0.144 & 0.046 & 0.092 \\
\hline
\end{tabular}

Figure 3. The scores of the efficiency of the policy measures for the market diffusion of ECVs 
Table 1. Challenges, opportunities and policy measures for the market diffusion of ECVs

\begin{tabular}{lll}
\hline \hline Challenge type & Challenge description & Number \\
\hline Financial & High purchase costs & C1 \\
& Missing publically available charging stations & C2 \\
Physical & Lack of service network & C3 \\
& Lack of service network in rural (outer) areas & C4 \\
& Unsuitability of ECVs for driving poor quality road in rural areas & C5 \\
Operational & ECV range as insufficient for daily tour needs of firms & C6 \\
& Recharging difficulties because of the stopping patterns of ECVs & C7 \\
Technological & unpredictability in winter conditions & C8 \\
& Trade-off between comfort (heat) and range during the winter & C9 \\
Psychological & Fear of accident involvement due to low noise level of ECVs & C10 \\
\hline Opportunity type & Opportunity description & Number \\
\hline \multirow{2}{*}{ Technological } & The perception of ECVs as cool to drive & O1 \\
Operational & Suitability of ECVs to firms' needs in terms of vehicle range & O2 \\
& Ease of adaption ECVs for the needs of firms & O3 \\
Environmental & Long-term benefits to the environment from driving ECVs & O4 \\
Financial & Advantages in terms of energy costs & O5 \\
& Potential opportunity for general cost savings & O6 \\
Branding & ECVs as a tool for generating good public image & O7 \\
& Opportunity for the firm to be a pioneer and innovator & O8 \\
\hline Policy type & Policy measure description & Number \\
\hline \multirow{2}{*}{ 'Carrots' } & Free parking for electric vehicles & P1 \\
& State subsidies for the purchase or use of electric vehicles, & P2 \\
& Low registration fee for electric vehicles & P3 \\
& Emission-based taxes on vehicles & P4 \\
& High petrol and diesel prices & P5 \\
& Cap on firms' carbon emissions & P6 \\
& Limitation on the purchase of conventional fuel vehicles but not on ECVs & P7 \\
\hline \hline
\end{tabular}


Table 2. The penetration rate of ECVs per target year

\begin{tabular}{lllll}
\hline \hline Participant & 2020 & 2030 & 2050 & 2070 \\
\hline$\# 1$ & $3 \%$ & $6 \%$ & $15 \%$ & $100 \%$ \\
$\# 2$ & $3 \%$ & $10 \%$ & $30 \%$ & $70 \%$ \\
$\# 3$ & $2 \%$ & $10 \%$ & $80 \%$ & $90 \%$ \\
$\# 4$ & $3 \%$ & $10 \%$ & $25 \%$ & $40 \%$ \\
$\# 5$ & $40 \%$ & $70 \%$ & $85 \%$ & $95 \%$ \\
$\# 6$ & $5 \%$ & $18 \%$ & $50 \%$ & $100 \%$ \\
$\# 7$ & $10 \%$ & $25 \%$ & $70 \%$ & $65 \%$ \\
$\# 8$ & $2 \%$ & $20 \%$ & $50 \%$ & $40 \%$ \\
$\# 9$ & $3 \%$ & $25 \%$ & $40 \%$ & $90 \%$ \\
$\# 10$ & $10 \%$ & $40 \%$ & $80 \%$ & $80 \%$ \\
$\# 11$ & $2 \%$ & $8 \%$ & $50 \%$ & $100 \%$ \\
$\# 12$ & $4 \%$ & $25 \%$ & $98 \%$ & $75 \%$ \\
$\# 13$ & $2 \%$ & $15 \%$ & $35 \%$ & $100 \%$ \\
$\# 14$ & $50 \%$ & $100 \%$ & $100 \%$ & $100 \%$ \\
$\# 15$ & $5 \%$ & $20 \%$ & $70 \%$ & $78 \%$ \\
$\# 16$ & $10 \%$ & $30 \%$ & $90 \%$ & $82 \%$ \\
\hline Geo Mean & $5 \%$ & $20 \%$ & $54 \%$ & \\
Average & $10 \%$ & $27 \%$ & $61 \%$ & \\
\hline \hline
\end{tabular}


Table 3. The distribution of activity pattern across the surveyed Danish firms

\begin{tabular}{llr}
\hline \hline Tour length & Description & Average share of tours \\
\hline & Daily tour of less than $49 \mathrm{~km}$ & $53.4 \%$ \\
& Daily tour between 50-99 km & $16.6 \%$ \\
& Daily tour between 100-149 km & $11.3 \%$ \\
& Daily tour of between 150-199 km & $7.1 \%$ \\
& Daily tour of more than 200 km & $11.6 \%$ \\
\hline Stop pattern & Description & Share of firms \\
\hline \hline & Less than 20\% of the vehicles in the firm have 30 min. stops \\
21-40\% of the vehicles in the firm's fleet have 30 min. stops & $37.2 \%$ \\
& $41-60 \%$ of the vehicles in the firm's fleet have 30 min. stops & $3.7 \%$ \\
& $61-80 \%$ of the vehicles in the firm's fleet have 30 min. stops & $7.2 \%$ \\
& $81-100 \%$ of the vehicles in the firm's fleet have 30 min. stops & $7.1 \%$ \\
Do not know how many vehicles have 30 min. stops & $42.2 \%$ \\
\hline
\end{tabular}


Table 4. Danish firm managers' perceptions regarding ECVs

\begin{tabular}{|c|c|c|c|c|c|c|}
\hline Challenge description & Number & $\begin{array}{l}\text { Strongly } \\
\text { disagree }\end{array}$ & Disagree & $\begin{array}{l}\text { Neither } \\
\text { agree nor } \\
\text { disagree }\end{array}$ & Agree & $\begin{array}{l}\text { Strongly } \\
\text { agree }\end{array}$ \\
\hline High purchase costs & $\mathrm{C} 1$ & 2.7 & 2.7 & 19.1 & 24.8 & 50.8 \\
\hline Missing publically available charging stations & $\mathrm{C} 2$ & 4.0 & 5.6 & 31.2 & 28.1 & 31.2 \\
\hline Lack of service network & $\mathrm{C} 3$ & 5.0 & 6.4 & 46.4 & 18.2 & 24.1 \\
\hline unpredictability of ECVs & $\mathrm{C} 8$ & 9.9 & 17.1 & 54.7 & 12.1 & 6.2 \\
\hline Fear of accidents due to low noise level & $\mathrm{C} 10$ & 20.2 & 19.9 & 48.7 & 8.0 & 3.1 \\
\hline Opportunity description & Number & & & & & \\
\hline The perception of ECVs as cool to drive & O1 & 4.3 & 7.2 & 52.1 & 20.2 & 16.1 \\
\hline Suitability of ECVs to firms' driving range & $\mathrm{O} 2$ & 15.7 & 17.6 & 19.6 & 25.3 & 21.9 \\
\hline Ease of adaption ECVs for the needs of firms & $\mathrm{O} 3$ & 7.7 & 7.8 & 59.7 & 13.1 & 11.7 \\
\hline Long-term benefits to the environment & $\mathrm{O} 4$ & 5.0 & 4.0 & 14.8 & 24.8 & 51.4 \\
\hline Potential opportunity for general cost savings & O6 & 11.5 & 9.7 & 37.7 & 17.7 & 23.3 \\
\hline ECVs as a tool for improving public image & $\mathrm{O} 7$ & 6.2 & 3.4 & 39.3 & 31.8 & 19.4 \\
\hline Policy measure description & Number & & & & & \\
\hline Free parking for electric vehicles & $\mathrm{P} 1$ & 7.5 & 5.8 & 33.5 & 21.7 & 31.5 \\
\hline Tax benefits for electric vehicles & $\mathrm{P} 3$ & 5.5 & 2.4 & 27.9 & 24.7 & 39.6 \\
\hline
\end{tabular}

